\title{
A SURVEY ON MOOC PROVIDERS FOR HIGHER EDUCATION
}

\author{
Dr. P. Malliga \\ Sr. System Analyst, Computer Centre, NITTTR, Chennai \\ pm.nitttr@gmail.com
}

\begin{abstract}
Online learning has evolved over the years, becoming increasingly accessible and gaining credibility as a learning medium. Universities are reshaping education on the Web by means of Massive Open Online Courses (MOOC). The learners can access educational content anytime, from anyplace and participatory culture using social networks seems to be the biggest advantage that MOOC has brought to the world of education especially in the higher education arena. MOOC has rapidly developed from a small section of specialist courses to millions of registered users on major online platforms offering hundreds of courses. As MOOC expands, attrition and accreditation is a problem. Though MOOC is expanding very fast, the literature on MOOC research is limited. This paper presents a survey on MOOC providers which aims to capture the state of MOOC, how they evolved and to identify issues and challenges that are important for MOOC providers.
\end{abstract}

\section{Indexing terms/Keywords}

Massive Open Online courses, MOOC, online learning, open education, Higher Education Institutions, pedagogy

\section{Academic Discipline and Sub-Disciplines}

Education, online learning, education methodology

\section{SUBJECT CLASSIFICATION}

Library of Congress Classification

\section{TYPE (METHOD/APPROACH)}

Literary Analysis; Survey

\section{Council for Innovative Research}

Peer Review Research Publishing System

Journal: International Journal of Management \& Information Technology

Vol. 7, No. 1

editor@cirworld.com

www.cirworld.com, member.cirworld.com 


\section{INTRODUCTION}

Higher Education is entering a phase of dramatic change and innovation particularly in offering online courses. MOOC (Massive Open Online Courses) is an online phenomenon gathering momentum over the past two years or so, which integrates the facilitation of an acknowledged expert in a field of study, the connectivity of social networking and a collection of freely accessible online resources. A MOOC is an online course with the option of free and open registration, a publicly shared curriculum, and open-ended outcomes. The term came into being in 2008, though versions of very large open online courses were in existence before that time [1]. MOOCs have been offered in conjunction with academic institutions or independently by facilitators.

MOOC builds on the active engagement of several hundred to several thousand "students" who self-organize their participation according to learning goals, prior knowledge and skills, and common interests. Although it may share in some of the conventions of an ordinary course, such as a predefined timeline and weekly topics for consideration, a MOOC generally carries no fees, no prerequisites other than Internet access and interest, no predefined expectations for participation, and no formal accreditation. The emergence of new educational delivery models including the rapid development of MOOCs is another source pressure on conventional Higher Education Institutions (HEI), but also offers opportunities for those institutions able to change and develop new provision [2].

\section{CHARACTERISTICS OF MOOC}

- Free: free non-degree online courses with open unlimited global enrollment to anyone who desires to learn, and regardless of their current educational level. Most of the MOOC are non-credit bearing, some are starting to offer certificates, enhanced learning services and credit options at additional costs.

- Online: Enrollment is done online at the MOOCs provider sites. Video lectures, online quizzes, online assignment, virtual labs and learning materials are provided online. Anyone can learn the MOOC courses offered online from anywhere using Internet and a laptop or a smart device.

- Participatory: All learners can interact either through email or discussion forum. The learning is collaborative, social and constructivist in nature.

- Instructors : Provide direction and a starting point to the learning intervention

- Distributed: New web technologies allow for scalable ways to deliver video lecture content, implement social forums and track student progress in MOOCs. The material is all over the internet: e-books, research papers, tweets, blogs etc

- Pedagogy: Many MOOCs use a video lecture style of pedagogy, repeating the old form of teaching using a new technology. New Teaching Technologies and Social Networking are essential to MOOC Format.

\section{TYPES OF MOOC BASED ON PEDAGOGY:}

Different ideologies have driven MOOCs in two distinct pedagogical directions namely $\mathrm{cMOOC}$ and $\mathrm{xMOOC}$. The distinct features of $\mathrm{CMOOC}$ and $\mathrm{XMOOC}$ are listed below:

\section{cMOOC}

- the connectivist MOOCs (CMOOC) are based on a connectivism theory of learning with networks developed informally [3];

- $\quad$ run on open source learning platforms and are led by academics as part of their university activity;

- pedagogical model is peer learning; $\mathrm{CMOOCs}$ encourage active exploration on the part of the learner, sharing with other learners, generating knowledge, and reflecting on learning [4][5];

- emphasize connected, collaborative learning and the courses are built around a group of like-minded individuals; platform to explore new pedagogies beyond traditional classroom settings;

- cMOOCs are associated particularly with their founding institutions Abathasca and Manitoba Universities in Canada.

\section{XMOOC}

- $\quad$ content-based MOOCs (xMOOCs), follows a more behaviourist approach [6];

- $\quad \mathrm{xMOOCs}$ are online versions of traditional learning formats (lecture, instruction, discussion etc.) on proprietary specialist software platforms owned by private enterprises;

- They feature contractual and commercial relationships between Universities who create content, and technology providers.

- Pedagogical model is dominated by the "drill and grill" instructional methods with video presentations, short quizzes and testing

- A further division of XMOOCs into two models can be identified: profit and non-profit to serve different purposes.

- the largest platform providers based on xMOOCs are edX, Udacity and Coursera and the UK's FutureLearn had joined this group during autumn 2013.

The blurring boundaries between the cMOOCs (based on learning process) and XMOOCs (based on learning content) are breaking down and MOOCs are increasingly run alongside campus traditional courses. The timeline of MOOC providers from US, Europe and other regions are listed in the next section. 


\section{TIMELINE OF MOOC PROVIDERS IN US}

- $\quad$ Early MOOCs emerged from the Open Educational Resources (OER) movement. The term MOOC was coined in 2008 by Dave Cormier and Bryan Alexander for an on-line course in "Connectivism and Connective Knowledge" offered by the University of Manitoba.

- From 2008 to 2011, a number of institutions experimented with the MOOC concept continuing in the open educational resources vein.

- 2012 became "The year of the MOOC" has dubbed by The New York Times and since then MOOC has become one of the hottest topics in education.

- Stanford University launched three courses in the fall of 2011, each of which had an enrollment of about 100,000 . The first course was "Introduction to Al", which was launched by Sebastian Thrun and Peter Norvig, had an enrollment of approximately 160,000 students.

- $\quad$ Following the publicity, Sebastian Thrun launched Udacity [7] and Daphne Koller and Andrew Ng launched Coursera. These two are for-profit companies. Coursera [8] subsequently announced partnerships with several other universities, including the University of Pennsylvania, Princeton University, Stanford University, and The University of Michigan [8].

- MIT launched the MITx not-for-profit, an effort to develop a free and open online platform. Harvard joined the initiative, renamed edX, and University of California, Berkeley joined in later. Then the University of Texas System, Wellesley College and the Georgetown University joined edX initiative [9].

- In November 2012, the first high school MOOC was launched by the University of Miami Global Academy, UM's online high school. In January 2013, Udacity launched MOOCs-for-credit, in collaboration with San Jose State University. In May 2013, the first entirely MOOC-based Master's Degree was announced, a collaboration between Udacity, AT\&T and the Georgia Institute of Technology, costing \$7,000.

- In June 2013, the University of North Carolina at Chapel Hill launched Skynet University, which offers MOOCs on the sole topic of introductory astronomy. Participants gained access to the university's global network of robotic telescopes, including telescopes in the Chilean Andes and Australia.

- In September 2013, edX announced a partnership with Google to jointly develop the edX open source learning platform. Google and edX will collaborate to build out and operate MOOC.org, a new site for non-xConsortium universities, institutions, businesses, governments and teachers to build and host their courses for a global audience.

Table 1 shows the major MOOC providers of US with number of courses offered, numbers of students registered and the number of institutions involved.

Table 1: Major MOOC providers of US

\begin{tabular}{|l|l|l|l|}
\hline MOOC platform & $\begin{array}{l}\text { Number of } \\
\text { Courses }\end{array}$ & $\begin{array}{l}\text { No. of } \\
\text { Students } \\
\text { registered }\end{array}$ & $\begin{array}{l}\text { No. of } \\
\text { Institutions }\end{array}$ \\
\hline Coursera & 481 & $17,000,000$ & 80 \\
\hline EdX & 75 & $4,000,000$ & 40 \\
\hline Udacity & 30 & 750,000 & 6 \\
\hline
\end{tabular}

\section{MOOC PROVIDERS OUTSIDE THE US}

- In Feb 2012, ex-Nokia employees in Finland launched Eliademy.com, based on the Open Source Moodle, Virtual Learning environment. The site is localized to more than 19 languages, designed for mobile use and hopes to compete with other MOOC platform [10].

- In October, 2012 The University of New South Wales in Australia launched UNSW Computing 1, the first MOOC by an Australian University. The course was also the first MOOC to run on OpenLearning [11], an online learning platform developed in Australia, which provides features for group work, automated marking, collaboration and gamification.

- In 15 March 2012 Researchers Dr. Jorge Ramió and Dr. Alfonso Muñoz from Universidad Politécnica de Madrid successfully launched the fist Spanish MOOC titled Crypt4you.

- In 18 June 2012, Ali Lemus from Galileo University launches the first Latin American MOOC titled "Desarrollando Aplicaciones para iPhone y iPad". This MOOC is a Spanish remix of Stanford University's popular "CS 193P iPhone Application Development" and had 5,380 students enrolled. The technology used to host the MOOC was the Galileo Educational System platform (GES) which is based on the .LRN project.

- In late 2012, the UK's Open University launched a British MOOC provider, Futurelearn, as a separate company including provision of MOOCs from non-university partners.

- In March 2013, Open2Study was set up in Australia. Both Futurelearn and Open2Study intend to build on the experience of their founding institutions in distance and online education. 
- In Brazil, the startup Veduca launched the first MOOCs in Brazil, in partnership with the University of São Paulo in June 2013.

- Other notable providers of MOOCs are based in Japan (Schoo) and Ireland (ALISON, with free online certificate/diploma courses and 2 million learners worldwide).

\section{MOOC INITIATIVES IN INDIA}

There is a growing interest in MOOCs in many developing countries like India and China.

- EduKart is an Indian distance learning cum online education company that provides Indian and international degrees. The business model is similar to a massive open online course (MOOC), with some specific features, e.g. most courses do not have a calendar-based schedule (students may start a course at any time); fees are charged for providing courses.

- During Dec 2012, a MOOC on "Software architecture and cloud computing" was offered for six weeks by Professor Prabhakar of Indian Institute of Technology, Kanpur (IITK) and Dr Balwinder Sodhi of IIT Ropar (IITR) [12]. They identified Canvas, an open source LMS, as the suitable platform and found it capable of scaling up even if several hundred learners connected at the same time. This was also an adequate tool for courseauthoring, discussion space and e-portfolios. Instead of depending on the platforms used by the 'big three' Coursera, Udacity and EdX, the team built all the components required to offer their own MOOC.

- During June 2013, IIT Bombay entered into an MoU with edX - a massive open online Course platform founded by Massachusetts Institute of Technology (MIT) and Harvard University to offer free Online university-level courses in a wide range of disciplines to a worldwide audience.

\section{VENTURES OF MOOC PROVIDERS}

There are around $30 \mathrm{MOOC}$ providers for Higher Education. Figure 1 shows the distribution of MOOC providers region wise. MOOC providers includes Alison, Canvas Network by Instructure, Carnegie Mellon University Open Learning Initiative, Class Central - Stanford, Coursera, MIT and Harvard led edX (MITx + Harvardx + BerkeleyX), and Udacity, , Curricki - open curriculua, , iTunesU - some courses - guide from DIY; iversity - Berlin-based MOOC provider, listing courses in English, Miríada X - Spanish / Portugese courses,MIT Open CourseWare [13], MOOC.fr , NovoEd, Open2Study (Australia), Open Education Europa, a Web site that aggregates MOOCs and other free online resources from European universities, Open Learning courses, Open Learn - Open University (UK), P2P University, SyMynd courses from NYU, University of Washington, McGill University, Stanford's Free Online Courses, Udacity courses, Udemy list of online courses, University of the People, WikiEducator content, Wikiversity - 'schools', Open Yale courses.

MOOCs are often taught by high-profile faculty on popular and diverse topics from Computer Science, Economics, Medicine, Literature, Engineering, Social Sciences and others. The list of American institutions offering MOOCs is growing exponentially. New institutions jump into MOOCs seemingly every week. There are around 25 best-colleges rankings for 2013 offer MOOCs or similar free offerings, including Harvard, Princeton, Yale, Columbia, MIT, Stanford, Duke, University of Pennsylvania, Cal Tech, Dartmouth, Northwestern, John Hopkins, Brown, Rice, Notre Dame, Vanderbilt, Emory, UC Berkeley, Carnegie Mellon, UCLA, and University of Virginia. Prestigious schools in Canada, Europe, Asia, the Middle East, and Australia also are offering or planning to offer MOOCs.

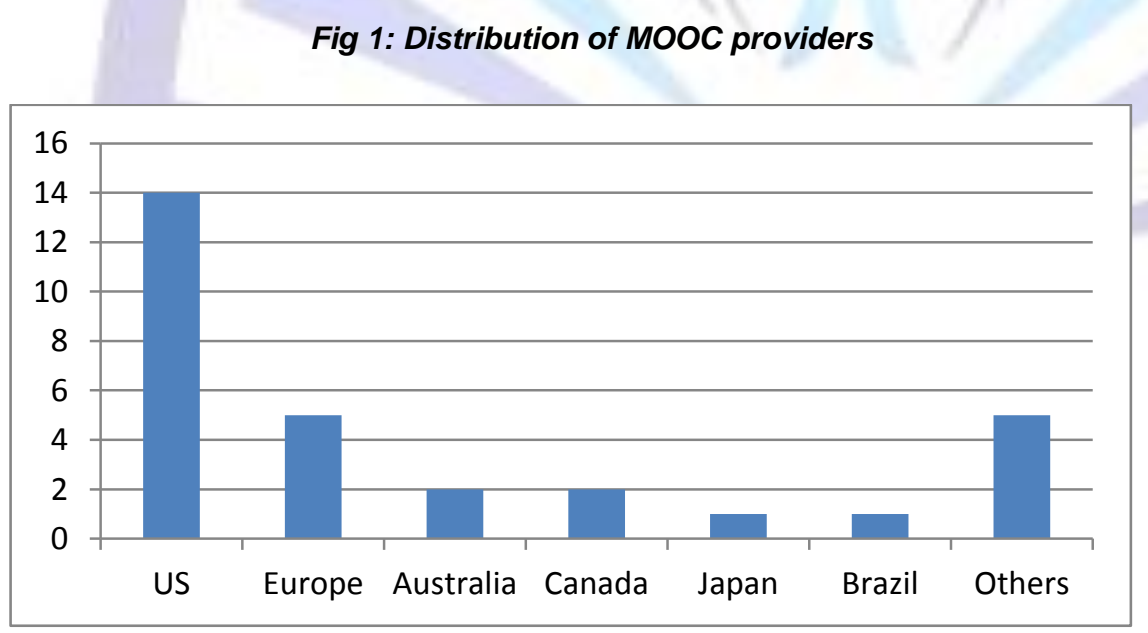

\begin{tabular}{|l|r|}
\hline Region & $\begin{array}{r}\text { No. of } \\
\text { MOOC } \\
\text { providers }\end{array}$ \\
\hline US & 14 \\
\hline Europe & 5 \\
\hline Australia & 2 \\
\hline Canada & 2 \\
\hline Japan & 1 \\
\hline Brazil & 1 \\
\hline Others & 5 \\
\hline
\end{tabular}

\section{ISSUES AND CHALLENGES FOR MOOC}

\section{Business Model}

The viability of MOOCs from an economic perspective is also a challenge. Most MOOC start-ups do not appear to have clear business models [14]. There is no standard business or financial model for how MOOCs will generate revenue. 
Some common approaches to generate revenue are considered by Coursera and other start-ups working in partnership with $\mathrm{HEl}$, including: charging students a fee for certificates of participation, certificates for completion or even transcripts; providing premium services such as recruiting tools that link employers with students who have shown ability in a given area; and philanthropic donations from individuals and companies.

\section{Pedagogy}

MOOCs are typically suited to more advanced learners who require less academic support to navigate their way through courses and materials [14]. However, only 7 to $10 \%$ of enrolled students complete the course. It is likely to increase as MOOC pedagogy and technology matures. Challenges exist in the area of finding new pedagogies and organizational mechanisms in MOOC to deliver a high quality learning experiences for different levels [15][16]. Specific pedagogical issues, challenges and questions include:

- $\quad$ the extent to which it can support deep enquiry and the creation of sophisticated knowledge;

- the breadth versus the depth of participation;

- $\quad$ whether and under what conditions successful participation can extend beyond those with broadband access and sophisticated social networking skills;

- $\quad$ specific strategies to maximize the effective contribution of facilitators in particular.

\section{Quality and Completion Rates}

The issue of quality assurance of MOOCs is a big concern for Higher Education Institutions. In most cases, compared to other online courses, MOOCs lack structure, and rarely include the central role of the instructor or teacher. Learners' motivation to participate in MOOCs is a significant area of interest to many Higher Education stakeholders. However, one of the most challenging aspects of MOOCs is attrition and accreditation, as the majority of learners will either drop out of the course entirely or complete the course without any transferable credits. There are many factors that influence students' motivation to learn; these include future economic benefit, development of personal and professional identity, challenge and achievement, enjoyment and fun. Surveys conducted by researchers at Duke University show that student motivations typically fell into one of four categories [17]:

- To support lifelong learning or gain an understanding of the subject matter, with no particular expectations for completion or achievement,

- For fun, entertainment, social experience and intellectual stimulation,

- Convenience, often in conjunction with barriers to traditional education options

- To experience or explore online education.

They are largely self-directed learning, which is a very different experience to formal education. MOOCs demand a certain level of digital literacy from the participants, which has raised concerns on inclusivity and equality of access.

\section{Assessment and Credit}

Most MOOC use quizzes as their main instrument of assessment - short multiple choice questions with automated answers for feedback [18]. Some may offer other types of assessment that require open responses, but with limited resources it is not possible for thousands of essay assignments to be marked by one lecturer. Some MOOCs rely heavily on peer engagement and assessment to support the individual student's learning process [19][20]. Coursera, for example, includes submission of essay style answers, graded through peer assessment, to balance the scale with the available resource. It also requires more staff resources and extensive structures for testing and validation. Some concerns are expressed around cheating and plagiarism with online learning, particularly where courses are eligible for academic credits.

Course providers have made clear from the beginning that they would not award credits for MOOCs, but only certificates of attendance and completion. Given that courses are free, awarding credits could become a threat on enrollment in regular courses. Measures are taken by MOOCs to avoid the issue for example Coursera teaming up with Pearson test centres to provide in person examinations. MOOCs often give participants opportunities to earn badges or a certificate of completion.

\section{CONCLUSIONS}

MOOC is changing the learning environment particularly in Higher Education Institutions [21]. It provides a platform for the learners for continuous learning, to upgrade and update their knowledge and skills from anywhere in the world. It also facilitates the learners to choose the appropriate courses offered by different prestigious Universities as it is open and free. As MOOC is expanding very fast and now even the smaller and less prestigious institutions want to adventure MOOC and they do not want to lose their market share and recruits. However MOOCs also provide institutions with a vehicle to think creatively and innovatively and to explore new pedagogical practices for learners motivation, participatory learning and also to satisfy individual learners need. MOOC has posed huge challenges for existing HEI business models, for institutions at all levels, for pedagogy, and for international educational demand.

\section{REFERENCES}

[1] Alexander McAuley, Bonnie Stewart, George Siemens and Dave Cormier (2010), The MOOC Model for Digital Practice. http://www.elearnspace.org/Articles/MOOC_Final.pdf 
[2] Mary (2012). How will MOOCs affect higher education?. The Udacity Blog. Retrieved from http://udacity.blogspot.in/2012/07/how-will-moocs-affect-higher-education.html

[3] Connectivism (n.d.). Wikipedia. http://en.wikipedia.org/wiki/Connectivism

[4] Shirky, C. (2010). Cognitive surplus: Creativity and generosity in a connected age. Toronto, ON, The Penguin Group

[5] Constructivism (n.d.) Wikipedia. http://en.wikipedia.org/wiki/Constructivism_(learning_theory)

[6] Lucas, S. (2013) Instructivism. Retrieved from: http://susanlucas.com/it/ail601/instructivism.html

[7] T. Lewin, 2012. "College of future could be come one, come all," New York Times (19 November), at http://www.nytimes.com/2012/11/20/education/colleges-turn-to-crowd-sourcing-courses.html,

[8] "Udacity," at http://www.udacity.com

[9] "Course Explorer," at https://www.coursera.org

[10] http://en.wikipedia.org/wiki/Massive open online course

[11] Open Learning Initiative. http://oli.cmu.edu/

[12] http://www.cse.iitk.ac.in/users/a4c/

[13] Open Courserware. http://ocw.mit.edu/courses/

[14] Li Yuan and Stephen Powell, JISC CETIS. March 2013, MOOCs and Open Education: Implications for Higher Education, A white paper, http://publications.cetis.ac.uk/2013/667

[15] Association for Learning Technology, (2012). "MOOC pedagogy: The challenges of developing for Coursera," Association for Learning Technology Newsletter, number 28, at http://newsletter.alt.ac.uk/2012/08/mooc-pedagogy-the- challenges-of-developing-for-coursera/

[16] D. Koller,(2012). "What we're learning from online education," at http://www.ted.com/talks/daphne_koller_what_we_re_learning_from_online_education.html

[17] Belanger, V., Thornton, J. (2013), Bioelectricity: A Quantitative Approach - Duke University's First MOOC

[18] Kimmerle, T.; Bohm, K. (2012), "Peer-Supervised Learning with Built-In Quality Control Based on Multiple-Choice Questions: A Case Study,(ICALT), IEEE 12th International Conference on Advanced Learning Technologies, pp.453,457, 4-6 July 2012 doi: 10.1109/ICALT.2012.87

[19] Siemens, G., Downes, S., and Cormier, D. (2012). How this course works.http://change.mooc.ca/how.htm

[20] Morrison, D., "Why and When Peer Grading is Effective for Open and Online Learning," Online Learning Insights, March 9, 2013.

[21] Siemens, G. (2012). MOOCs are really a platform. elearnspace. Retrieved from:http://www.elearnspace.org/blog/2012/07/25/moocs-are-really-a-platform/

\section{Author's Biography}

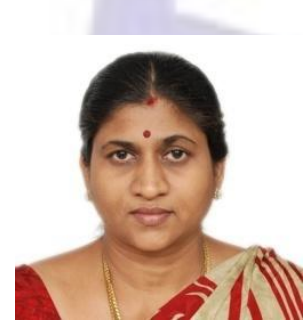

Dr. P. Malliga is currently working as Sr. System Analyst in Computer Centre NITTTR, Chennai. She joined Computer Centre, NITTTR as Lecturer in 1996. She has been teaching Computer Science Subjects and Pedagogy for Polytechnic and Engineering Teachers. She holds a Bachelor degree in Computer Science and Engineering. She also got her Master of Science by research from Anna University. She got her Doctor of Computer Science \& Engineering Education from University of Madras. She has published a number of research papers in the area of Databases, Text Mining and E-learning. 